\title{
A Study on Management of Basicervical Neck Femur Fractures with Dynamic Hip Screw (DHS) and Derotation Screw Fixation
}

Malay Kumar Saha ${ }^{*}$, Mohammad Jahangir Alam², Rezaul Karim³, Md. Zakir Hossain ${ }^{4}$, Joyosree Paul ${ }^{5}$, Chitta Ranjan Debnath $^{6}$, Lakshman Chandra Barai ${ }^{7}$, Md. Zanzibul Tareq ${ }^{8}$, Abu Jafar Md. Tareq Morshed ${ }^{8}$

\footnotetext{
${ }^{1}$ Associate Professor, Unit Chief, Department Of Orthopaedic Surgery, MBBS, D-Ortho, MS-Ortho, Mymensingh Medical College, Mymensingh, Bangladesh

${ }^{2}$ Professor, National Institute of Traumatology and Orthopaedic Rehabilitation, Dhaka, Bangladesh

${ }^{3}$ Associate Professor, National Institute of Traumatology and Orthopaedic Rehabilitation, Dhaka, Bangladesh

${ }^{4}$ Associate Professor and Classified Specialist, Dept. of Otolaryngology \& Head-Neck Surgery, MBBS, MCPS, DLO, FCPS, FACS (USA), FRCS (Glasg), Combined Military Hospital, Dhaka Cantonment, Dhaka, Bangladesh

${ }^{5}$ Medical Officer (OPD), Mymensingh Medical College Hospital, Mymensingh, Bangladesh

${ }^{6}$ Principal \& Professor, Department of Hepatology, Mymensingh Medical College, Char Para, Medical Rd, Mymensingh 2200, Bangladesh

${ }^{7}$ Assistant Professor, Cardiology, MBBS, D.CARD, MCPS, National Institute of Cardiovascular Diseases and Hospital, Dhaka, Bangladesh

${ }^{8}$ Assistant Registrar, Cardiac Surgery, National Institute of Cardiovascular Diseases (NICVD), Dhaka, Bangladesh
}

DOI: $\underline{10.36347 / \text { sasjs.2020.v06i08.005 }}$

| Received: 07.08.2020 | Accepted: 18.08.2020 | Published: 26.08.2020

*Corresponding author: Malay Kumar Saha

Abstract

Original Research Article

Background: Basicervical fractures of femur represent an intermediate form of injury between the neck femur fractures andintertrochanteric fractures, with no clear-cut guidelines for fixation. The purpose of this study was to evaluate the effectiveness of DHS and derotation screw fixation in the management of basicervical fractures of femur. Objective: To find out the Management of Basicervical Neck Femur Fractures With Dynamic Hip Screw (DHS) And Derotation Screw Fixation. Methods: This was a prospective observational study conducted on 26 patients of either sex with an average age of 52.46 years, presenting to the department of orthopaedic surgery of Mymensingh Medical College \& Hospital (MMCH), Mymensingh, Bangladesh \& National Institute of Traumatology and Orthopaedic Rehabilitation (NITOR), Dhaka, Bangladesh in between January 2018 and December 2019, with a diagnosis of basicervical neck femur fracture. All the patients underwent closed reduction and internal fixation with dynamic hip screw (DHS) and derotation screw. The patients were followed up for a period of 1 year. The patients were analysed for union and functional results using the modified Harris hip score. Results: All the fractures united and the average time of union was 14.4 weeks. The modified Harris hip score at follow up was excellentin 14(53.84\%), good in $8(30.77 \%)$, fair in $3(11.54 \%)$ and poor in $1(3.85 \%)$ patients respectively. Conclusions: Thus results of our study demonstrate that closed reduction and internal fixation with DHS and derotation screw is a safeand effective surgical procedure for the treatment of basicervical neck femur fractures.

Keywords: Basicervical Neck Femur Fracture, Closed Reduction \& internal Fixation, Dynamic Hip Screw, Derotation Screw.

Copyright @ 2020: This is an open-access article distributed under the terms of the Creative Commons Attribution license which permits unrestricted use, distribution, and reproduction in any medium for non-commercial use (NonCommercial, or CC-BY-NC) provided the original author and source are credited.

\section{INTRODUCTION}

Basicervical fracture is a fracture through the base of femoral neck at its junction with the intertrochanteric region. Due to this location, it represents an intermediate form between femoral neck, usually fixed with multiple cancellous screws, and the intertrochanteric fracture, fixed with a sliding screw device. Basicervical neck femur fractures are rare type of fractures located just proximal to or along the intertrochanteric line [1]. Although it is generally acknowledged that basicervical fractures are extra capsular, this may not always be the case [2]. Basicervical fractures are thus at greater risk for osteonecrosis than the more distal intertrochanteric fractures. Furthermore, basicervical fractures lack the cancellous interdigitation seen with fractures through the intertrochanteric region and are more likely to sustain rotation of the femoral head during implant insertion. Traditionally, most intracapsular neck femur fractures in young adults have been treated with cancellous cannulated screws (CCS) whereas 
Malay Kumar Saha et al., SAS J Surg, August, 2020; 6(8): 304-309

intertrochanteric fractures have been managed well in the past with the dynamic hip screw (DHS). But since the basicervical fractures are intermediate between them, so a controversy exists whether to use CCS or DHS for stabilization of these fractures. Moreover, these fractures have long been considered to be inherently unstable which makes the ideal choice of implant for their fixation more difficult $[3,7]$. The use of DHS alone for fixation of these fractures may lead to poor results, due to biomechanically unstable nature of this fixation $[8,12]$. Thus, these fractures should be treated by a method which blends the principles of fixation of both neck femur and intertrochanteric fractures. The DHS and derotation screw fixation construct provides both sliding capacity and rotational stability for the management of basicervical neck femur fractures. In the present study we evaluated the effectiveness of closed reduction and internal fixation with dynamic hip screw and derotation screw in the management of basicervical neck femur fractures through the assessment of: (a) Attainment of union, (b) Functional results using the Modified Harris Hip Score. However, because basicervical fractures have greater instability than stable intertrochanteric fractures $[8,10]$ poor functional outcome may be expected when the DHS is used alone [10-12].

\section{OBJECTIVE}

To find out the Management of Basicervical Neck Femur Fractures With Dynamic Hip Screw (DHS) And Derotation Screw Fixation.

\section{MATERIALS AND METHODS}

After approval by the institutional ethics committee and informed written consent, the study was started. This was a prospective observational study conducted on 26 patients of either sex with an average age of 52.46 years, presenting to the Dept. of orthopaedic surgery of Mymensingh Medical College \& Hospital (MMCH), Mymensingh, Bangladesh and National Institute of Traumatology and Orthopaedic Rehabilitation (NITOR), Dhaka, Bangladesh \& in between January 2018 and December 2019, with a diagnosis of basicervical neck femur fracture. The sex distribution was 17 males and 9 females.

\section{Inclusion Criteria}

1. Age greater than 18 years.

2. Closed basicervical neck femur fracture.

3. Ambulatory patient before the fracture.

\section{Exclusion Criteria}

1. Age less than 18 years.

2. Open fractures.

3. Patients with blebs and bed sores.

4. Non ambulatory patient before the injury.

5. Patients with multiple associated fractures.

At presentation all the patients were thoroughly examined and neurovascular assessment was done. Standard anteroposterior radiograph of the pelvis and anteroposterior and lateral radiographs of the injured hip were obtained. Below knee Buck's traction was applied. The patients were admitted and preoperative anaesthetic checkup was done. The surgery was done as soon as the patients obtained anaesthetic clearance. The surgical procedure was explained to the patients and informed written consent was taken.

\section{Surgical Technique}

After administration of spinal anaesthesia, the patients were placed in supine position on the fluorescent fracture table. Under fluoroscopic guidance closed reduction was done by traction and internal rotation of the affected limb. The painting and draping of the surgical site was done. Standard lateral skin incision was given in the proximal thigh just below the greater trochanter, tensor fascia lata was cut and vastus lateralis was split in an L shaped fashion. Bone levers were inserted and the trochanteric flare was identified. Guide wire was inserted with the help of angle guide 2 $\mathrm{cm}$ below the vastus lateralis ridge. Correct central placement of the guide wire was confirmed under $\mathrm{C}$ arm in both the anteroposterior and lateral views. Another guide wire was inserted superior and parallel to the first wire. The lag screw length was calculated with the help of another guide wire and the triple reamer was set for the appropriate length. Triple reaming was done with the help of power drill. Lag screw of appropriate length was inserted over the guide wire. A $6.5 \mathrm{~mm}$ cannulated cancellous of appropriate length was inserted over the superior guide wire to act as the derotation screw. DHS side plate was inserted and compression screw was inserted over the lag screw. Haemostasis was achieved, suction drain was inserted and the wound was closed in a standard fashion. Antiseptic dressing was done and the patient was shifted out of the operation theatre. Standard postoperative care pathway was followed for these patients. The drains were removed after 48 hours and postoperative AP and lateral radiographs were taken. Knee range of motion was started and non-weight bearing ambulation with walker was allowed. The average duration of hospital stay was 7 days. 6 patients required blood transfusions. At the time of discharge patients were instructed about physiotherapy and weight bearing protocols. The sutures were removed after 15 days of surgery. For the first 2 months patients were asked to follow up at 2 week intervals and later on once a month for a period of 1 year following surgery. At follow ups standard AP and lateral radiographs of hip were taken. Weight bearing was gradually increased according to callus formation visible on radiographs. Walking aids were discarded at 6 to 8 weeks after surgery. The fracture was defined as united if a minimum of 3 cortices showed bridging callus on radiographs. The patients were followed up for a period of 1 year and after this period all the data collected was subjected to analysis. 
Malay Kumar Saha et al., SAS J Surg, August, 2020; 6(8): 304-309

\section{STATISTICAL METHODS}

The data was analysed with SPSS version 19.0 software. The demographic variables were assessed by number and percentage. Simple arithmetic mean was used for the description of the values of the time taken for union in weeks. Functional results were assessed by the measurement of Modified Harris Hip Score.

Modified Harris Hip Score: This score was used for assessment of the functional results. The score was graded as Excellent 90-100, Good 80-90, Fair 70-80 and Poor $<70$.

Table-1: Modified Harris hip score.

\begin{tabular}{|c|c|c|c|c|c|c|c|}
\hline \multirow[t]{2}{*}{ Pain } & & \multicolumn{2}{|l|}{ Function: Gait } & \multirow[b]{2}{*}{ Stairs } & \multicolumn{2}{|c|}{ Functional Activities } & \multirow[b]{2}{*}{$\begin{array}{l}\text { Public } \\
\text { transportation }\end{array}$} \\
\hline & Limp & Support & $\begin{array}{l}\text { Distance } \\
\text { walked }\end{array}$ & & Socks/Shoes & Sitting & \\
\hline $\begin{array}{l}\text { None/ignores } \\
\text { (44points) }\end{array}$ & None (11points) & $\begin{array}{l}\text { None }(11 \\
\text { points) }\end{array}$ & $\begin{array}{l}\text { Unlimited } \\
\text { (11points) }\end{array}$ & $\begin{array}{l}\text { Normally (4 } \\
\text { points) }\end{array}$ & $\begin{array}{l}\text { With ease (4 } \\
\text { points) }\end{array}$ & $\begin{array}{l}\text { Any chair, } 1 \\
\text { hour ( } 5 \text { points })\end{array}$ & $\begin{array}{l}\text { Able to enter } \\
\text { public } \\
\text { transportation } \\
\text { (1 points) }\end{array}$ \\
\hline $\begin{array}{l}\text { Slight, occasional, } \\
\text { no compromise in } \\
\text { activity ( } 40 \text { points) }\end{array}$ & Slight (8 points) & $\begin{array}{l}\text { Cane, long } \\
\text { walks ( } 7 \\
\text { points) }\end{array}$ & $\begin{array}{l}6 \text { blocks ( } 8 \\
\text { points) }\end{array}$ & $\begin{array}{l}\text { Normally } \\
\text { with } \\
\text { banister (2 } \\
\text { points) }\end{array}$ & $\begin{array}{l}\text { With } \\
\text { difficulty } \\
\text { ( } 2 \text { points) }\end{array}$ & $\begin{array}{l}\text { High chair, } 1 / 2 \\
\text { hour ( } 3 \text { points) }\end{array}$ & $\begin{array}{l}\text { Unable to use } \\
\text { public } \\
\text { transportation } \\
\text { (0 points) }\end{array}$ \\
\hline $\begin{array}{l}\text { Mild, no effect on } \\
\text { ordinary activity, } \\
\text { pain after activity, } \\
\text { uses aspirin ( } 30 \\
\text { points) }\end{array}$ & $\begin{array}{l}\text { Moderate ( } 5 \\
\text { points) }\end{array}$ & $\begin{array}{l}\text { Cane, full time } \\
\text { ( } 5 \text { points) }\end{array}$ & $\begin{array}{l}2-3 \text { blocks } \\
\text { ( } 5 \text { points })\end{array}$ & $\begin{array}{l}\text { Any method } \\
\text { (1 points) }\end{array}$ & $\begin{array}{l}\text { Unable (0 } \\
\text { points) }\end{array}$ & $\begin{array}{l}\text { Unable to sit, } 1 / 2 \\
\text { hour, any chair } \\
\text { (0 points) }\end{array}$ & \\
\hline $\begin{array}{l}\text { Moderate, } \\
\text { tolerable, makes } \\
\text { concessions, } \\
\text { occasional codeine } \\
\text { ( } 20 \text { points) }\end{array}$ & $\begin{array}{l}\text { Severe }(0 \\
\text { points) }\end{array}$ & $\begin{array}{l}\text { Crutch (4 } \\
\text { points) }\end{array}$ & $\begin{array}{l}\text { Indoors only } \\
\text { ( } 2 \text { points) }\end{array}$ & $\begin{array}{l}\text { Not able }(0 \\
\text { points })\end{array}$ & & & \\
\hline $\begin{array}{l}\text { Marked, serious } \\
\text { limitations ( } 10 \\
\text { points) }\end{array}$ & $\begin{array}{l}\text { Unable to walk } \\
\text { ( } 0 \text { points })\end{array}$ & $\begin{array}{l}2 \text { canes }(2 \\
\text { points })\end{array}$ & $\begin{array}{l}\text { Bed and } \\
\text { chair }(0 \\
\text { points })\end{array}$ & & & & \\
\hline \multirow[t]{2}{*}{$\begin{array}{l}\text { Totally disabled }(0 \\
\text { points })\end{array}$} & & $\begin{array}{l}2 \text { crutches (1 } \\
\text { points) }\end{array}$ & & & & & \\
\hline & & $\begin{array}{l}\text { Unable to } \\
\text { walk } \\
\text { (0 points) }\end{array}$ & & & & & \\
\hline
\end{tabular}

\section{RESULTS}

This was a prospective observational study. The fractures of all the patients in this study united with an average duration of 14.4 weeks. The Modified Harris Hip score at follow up was excellent in 14(53.84\%), good in $8(30.77 \%)$, fair in $3(11.54 \%)$ and poor in $1(3.85 \%)$ patients respectively. Two patients developed superficial skin infections which resolved with antibiotics and local drainage. One patient had implant failure and needed revision.

Table-2: Age Distribution ( $\mathrm{N}=26)$

\begin{tabular}{|l|l|l|}
\hline Age in years & No. of patients & Percentage (\%) \\
\hline $20-30$ & 2 & 7.69 \\
\hline $31-40$ & 3 & 11.54 \\
\hline $41-50$ & 6 & 23.08 \\
\hline $51-60$ & 10 & 38.46 \\
\hline $61-70$ & 5 & 19.23 \\
\hline Total & 26 & 100.0 \\
\hline
\end{tabular}


Table-3: Sex Distribution

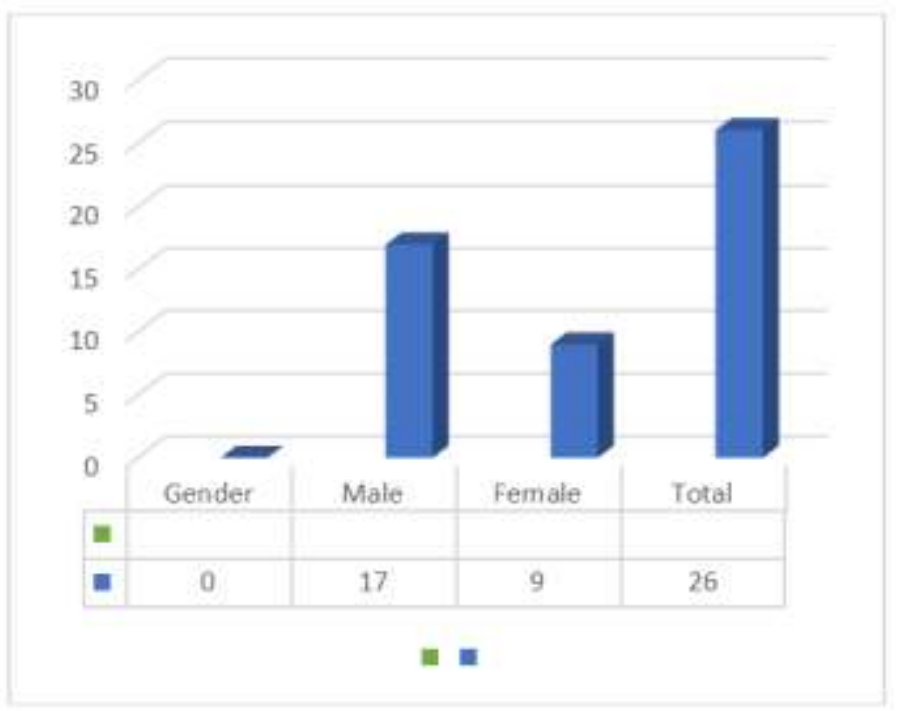

Table-4: Table depicting the results of the study $(\mathrm{N}=26)$

\begin{tabular}{|l|l|l|l|l|l|l|}
\hline Parameters & \multicolumn{2}{|l|}{$\begin{array}{l}\text { Mean age of the } \\
\text { patient's in years. }\end{array}$} & $\begin{array}{l}\text { Mean time taken for } \\
\text { union in weeks. }\end{array}$ & \multicolumn{3}{|l|}{$\begin{array}{l}\text { Modified Harris Hip Score at follow up in various } \\
\text { patients by number and percentage. }\end{array}$} \\
\hline $\begin{array}{l}\text { Values of the } \\
\text { parameters. }\end{array}$ & 52.46 & 14.4 & Excellent & Good & Fair & Poor \\
\cline { 4 - 7 } & & $14(53.84 \%)$ & $8(30.77 \%)$ & $3(11.54 \%)$ & $1(3.85 \%)$ \\
\hline
\end{tabular}



Fig-1: Anteroposterior radiograph of the hip showing basicervical neck femur fracture

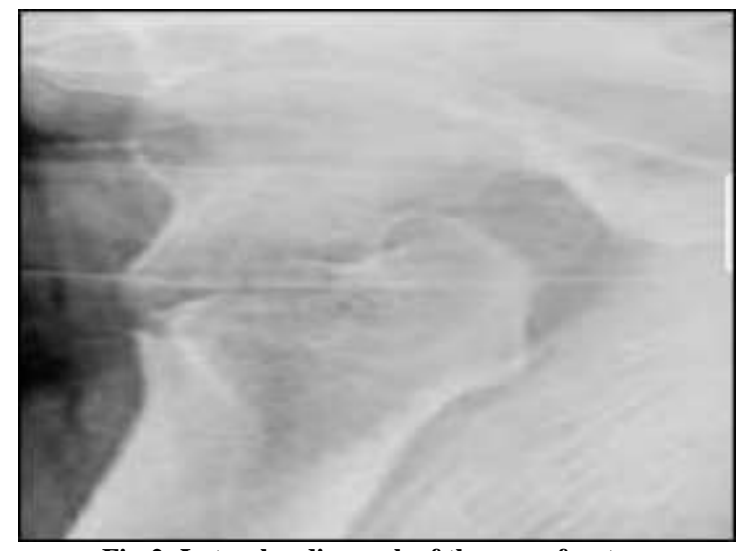

Fig-2: Lateral radiograph of the same fracture

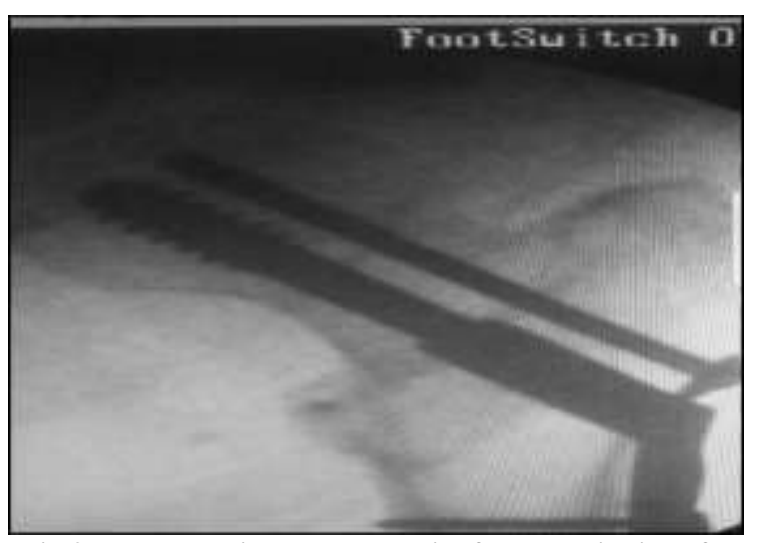

Fig-3: Intraoperative anteroposterior fluoroscopic view of a basicervical fracture after fixation with DHS and derotation screw

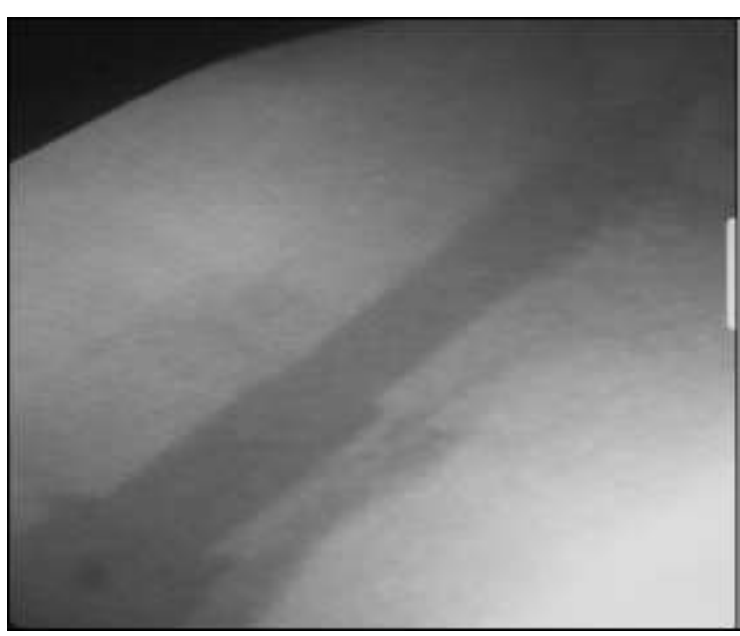

Fig-4: Intraoperative lateral fluoroscopic view of the same fracture 


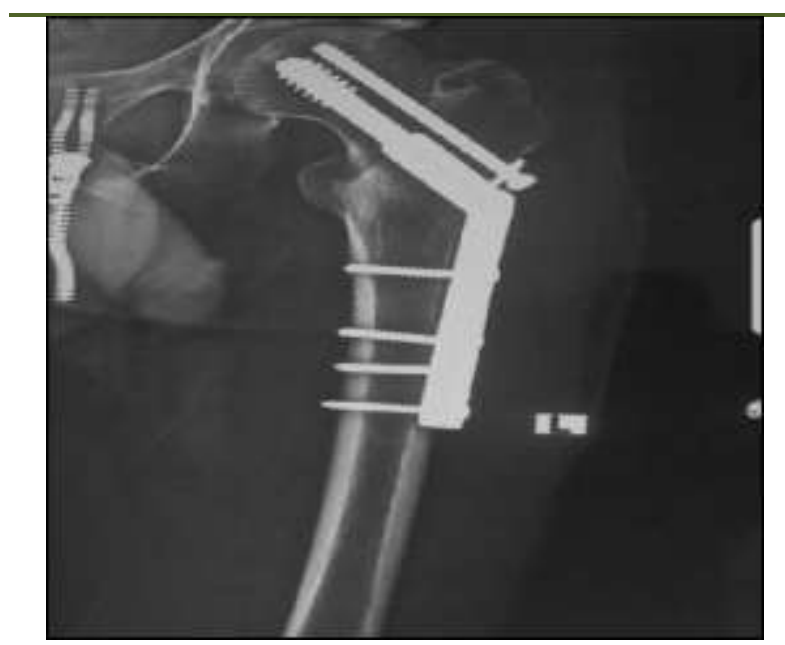

Fig-5: Follow up anteroposterior radiograph of the same patient depicting union at the fracture site

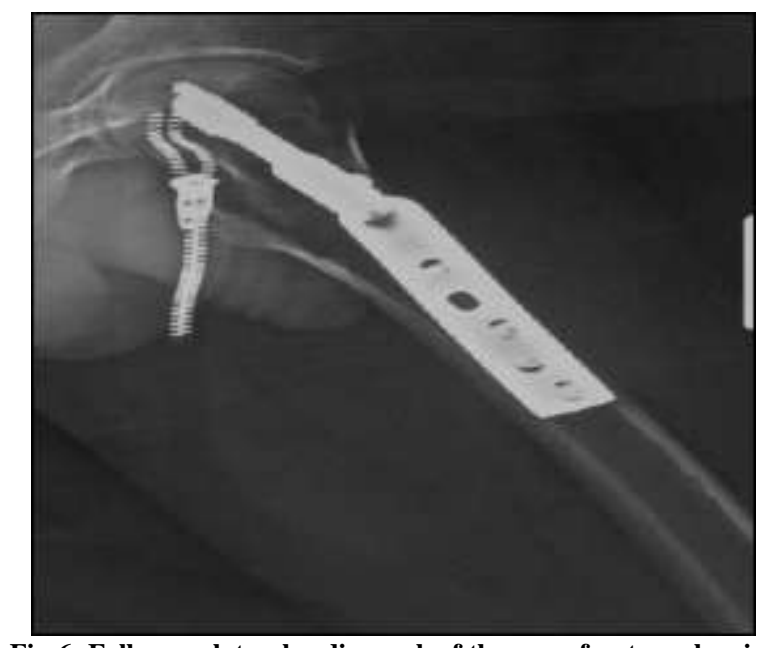

Fig-6: Follow up lateral radiograph of the same fracture showing unionat the fracture site

\section{DISCUSSION}

Basicervical fracture neck of femur, an intermediate form between femoral neck and intertrochanteric fractures has been defined as a basal fracture of the femoral neck in which the fracture runs along the line of the anterior attachment of the capsule [13]. This area represents the transition zone between intracapsular femoral neck and extracapsular intertrochanteric fracture [14]. These fractures are relatively unstable as compared to the simple intertrochanteric fractures, due to extracapsular location of its fracture line $[1,15,16]$, high fracture angle $[8,11]$ absence of muscular attachment in the proximal fragment, [15] and separation of head-neck fragment from the trochanters leading to rotational instability [2, 11, 17, 18]. Proper management of these fractures presents a unique challenge to the orthopaedic surgeon

fractures. Since these fractures have characteristics of both neck femur and intertrochanteric fractures, thus combining the principles of fixation of both these fractures is required for the attainment of satisfactory results. The dynamic hip screw (DHS) and derotation screw combination due to the properties of sliding capacity and rotational stablility, provides a biomechanically stable fixation construct for these fractures. In our present study, we evaluated the effectiveness of closed reduction and internal fixation with dynamic hip screw and derotation screw in the management of basicervical neck femur fractures in relation to achievement of union and functional results. Modified Harris Hip score [19] (Table-1) was used for the assessment of functional results. This was a prospective observational study conducted on 26 patients of either sex (Table-3) with an average age of 52.46 years (Tables $2 \& 4$.) with the diagnosis of basicervical neck femur fracture (Figures $1 \& 2$ ). All the patients underwent closed reduction and internal fixation with DHS and derotation screw (Figures 3 \& $4)$. The fractures of all the patients in this study united (Figures $5 \& 6$.) with an average duration of 14.4 weeks (Table-4). Majority of the patients in our study had satisfactory functional results at follow up. The Modified Harris Hip score (Table-4) at follow up was excellent in $14(53.84 \%)$, good in $8(30.77 \%)$, fair in $3(11.54 \%)$ and poor in $1(3.85 \%)$ patients respectively. Two patients developed superficial skin infections which resolved with antibiotics and local drainage. One patient had implant failure and needed revision. The results of our study are quite comparable to other studies [20-22] done about this procedure. In the study by Agarwal et al., [20] the number of patients was 30, the average time taken for union was 13 weeks, and the Modified Harris hip score was excellent in $73.33 \%$ cases, good result $16.67 \%$ and poor in $10 \%$ of cases, which compares quite favourably to our study. In the study by Nitharwal et al., [21] 30 patients were included in the DHS group, the average time for union was 13.1 weeks, and the Modified Harris hip score was excellent in $26.67 \%$, good in $23.33 \%$, fair in $36.67 \%$ and poor in $13.33 \%$ of cases, which compares quite favourably to our study. In the study by Sharma et al., [22] 28 patients were included in the DHS group, the average time for union was13.9 weeks and the Modified Harris Hip Score was good to excellent in $83.3 \%$ of the patients which compares quite favourably to our study.

\section{CONCLUSION}

From the above analysis we can infer that closed reduction and internal fixation with dynamic hip screw (DHS) and derotation screw is a safe and 
Malay Kumar Saha et al., SAS J Surg, August, 2020; 6(8): 304-309

effective surgical procedure for the management of basicervical neck femur fractures with a high rate of union and excellent functional results.

\section{REFERENCES}

1. Saarenpaa I, Partanen J, Jalovaara P. Basicervical fracture-a rare type of hip fracture. Arch Orthop Trauma Surg. 2002; 122:69-72.

2. Swiontkowski MF. Intracapsular fractures of the hip. J Bone Joint Surg Am. 1994; 76(1):129-38.

3. Chen CY, Chiu FY, Chen CM, Huang CK, Chen WM, Chen TH. Surgical treatment of basicervical fractures of femur-a prospective evaluation of 269 patients. Journal of Trauma and Acute Care Surgery. 2008 Feb 1;64(2):427-9.

4. Kuokkanen HO. Treatment options for basicervical fractures of the femoral neck: a clinical follow-up. Acta Orthop Belg.1991; 57(2):162-68.

5. Levy RN, Siegel M, Sedlin ED, Siffert RS. Complications of Ender-pin fixation in basicervical, intertrochanteric, and sub trochanteric fractures of the hip. J Bone Joint Surg Am. 1983; 65(1):66-69.

6. Massoud EI. Fixation of basicervical and related fractures. Int Orthop. 2010; 34(4):577-82.

7. Su BW, Heyworth BE, Protopsaltis TS, Lipton $\mathrm{CB}$, Sinicropi SM, Chapman CB, et al. Basicervical versus intertrochanteric fractures: an analysis of radiographic and functional outcomes. Orthopedics. 2006; 29(10):919-25.

8. Blair B, Koval KJ, Kummer F, Zuckerman JD. Basicervical fractures of the proximal femur. A biomechanical study of 3 internal fixation techniques. Clin Orthop Relat Res. 1994; 306:256263.

9. Deneka DA, Simonian PT, Stankewich CJ. Biomechanical comparison of internal fixation techniques for the treatment of unstable basicervical femoral neck fractures. J Orthop Trauma. 1997; 11:337-343.

10. Gill JM, Johnson GR, Sher JL, Kornjaca NA. Biomechanical aspects of the repair of intertrochanteric fractures. J Biomed Eng. 1989; 11:235-239.

11. Ly TV, Swiontkowski MF. Management of femoral neck fracture in young adult. IJO. 2008; 42:3-12.
12. Ort PJ, La Mont J. Treatment of femoral neck fractures with a sliding compression screw and two Knowles pins. Clin. Orthop. 1984; 190:158162.

13. Parker MJ, Pryor GA, Thorngren KG. Extra medullary fixation of extracapsular fractures. Handbook of hip fracture surgery. ButterworthHeinemann, Oxford, 1997, 63-90.

14. Deneka DA, Simonian PT, Stankewich CJ, Eckert D, Chapman JR, Tencer AF. Biomechanical comparison of internal fixation techniques for the treatment of unstable basicervical femoral neck fractures. Journal of orthopaedic trauma. 1997 Jul 1;11(5):337-43.

15. DeLee JC. Fractures and dislocations of the hip. In: Rockwood and Green's fracture in adults, 4th ed. Lippincott-Raven, Philadelphia, 1996.

16. Müller ME, Allgöwer M, Schneider R. Proximal femur. In: Manual of internal fixation: techniques recommended by the AO-ASIF Group, 3rd edn. Springer, Berlin, 1992.

17. Jensen JS. Classification of trochanteric fractures. Acta Orthop Scand. 1980; 51:803-810.

18. Smith FB. Effects of rotary and valgus malpositions of blood supply to the femoral head. J Bone Joint Surg. 1959; 41A:800-815.

19. Harris WH. Traumatic arthritis of the hip after dislocation and acetabular fractures: treatment by mold arthroplasty. An end-result study using a new method of result evaluation. J Bone Joint Surg Am. 1969; 51(4):737-55.

20. Agarwal B, Frank HC, Bhatacharya TDA. Choudhury F, Roy R. Basicervical Fracture of Neck Femur Treated with DHS And Derotation Screw- A Prospective Study of 30 Cases. IOSR Journal of Dental and Medical Sciences. 2017; 16:37-40.

21. Nitharwal ML, Kumar S, Harshwal RK, Jain MP, Mehra AK. A Prospective comparative study of outcome of surgical management of basicervical fractures of femur with dynamic hip screw (DHS) with derotation screw and multiple cannulated cancellous (CC) screw. International Journal of Contemporary Medical Research. 2016; 3(7):2119-2122.

22. Sharma A, Sethi A, Sharma S. Comparative analysis of treatment of basicervical femur fractures in young adults with CCS, DHS, and PFN. REV BRAS ORTOP. 2018; 53(6):783-787. 